\title{
New insights in Staphylococcus pseudintermedius pathogenicity: antibiotic-resistant biofilm formation by a human wound-associated strain
}

\author{
Arianna Pompilio ${ }^{1,2}$, Serena De Nicola ${ }^{1,2}$, Valentina Crocetta ${ }^{1,2}$, Simone Guarnieri ${ }^{2,3}$, Vincenzo Savini ${ }^{4}$, \\ Edoardo Carretto ${ }^{5}$ and Giovanni Di Bonaventura ${ }^{1,2^{*}}$
}

\begin{abstract}
Background: Staphylococcus pseudintermedius is an opportunistic pathogen recognized as the leading cause of skin, ear, and post-operative bacterial infections in dogs and cats. Zoonotic infections have also recently been reported causing endocarditis, infection of surgical wounds, rhinosinusitis, and catheter-related bacteremia. The aim of the present study is to evaluate, for the first time, the pathogenic potential of S. pseudintermedius isolated from a human infection. To this end, strain DSM 25713, which was recently isolated from a wound of a leukemic patient who underwent a bone marrow transplantation, was investigated for biofilm formation and antibiotic-resistance under conditions relevant for wound infection.

Results: The effect of $\mathrm{pH}(5.5,7.1$, and 8.7) and the presence of serum (diluted at 1:2, 1:10, and 1:100) on biofilm formation was assessed through a crystal violet assay. The presence of serum significantly reduced the ability to form biofilm, regardless of the $\mathrm{pH}$ value tested. In vitro activity of eight antibiotics against biofilm formation and mature 48 h-old biofilms was comparatively assessed by crystal violet assay and viable cell count, respectively. Antibiotics at sub-inhibitory concentrations reduced biofilm formation in a dose-dependent manner, although cefoxitin was the most active, causing a significant reduction already at 1/8xMIC. Rifampicin showed the highest activity against preformed biofilms (MBEC 90 : $2 x M I C)$. None of the antibiotics completely eradicated the preformed biofilms, regardless of tested concentrations. Confocal and electron microscopy analyses of mature biofilm revealed a complex "mushroom-like" architecture consisting of microcolonies embedded in a fibrillar extracellular matrix.
\end{abstract}

Conclusions: For the first time, our results show that human wound-associated S. pseudintermedius is able to form inherently antibiotic-resistant biofilms, suggestive of its pathogenic potential, and consistent with recent reports of zoonotic infections.

Keywords: Staphylococcus pseudintermedius, zoonotic infection, Biofilm formation, Wound infection, Antibiotic-resistance

\section{Introduction}

Staphylococcus pseudintermedius, the prevalent species in the Staphylococcus intermedius Group, is an opportunistic pathogen recognized as the leading cause of skin, ear, and post-operative bacterial infections in dogs and cats $[1,2]$.

\footnotetext{
* Correspondence: gdibonaventura@unich.it

'Department of Medical, Oral, and Biotechnological Sciences, "G. d'Annunzio" University, Via Vestini 31, Chieti 66100, Italy

${ }^{2}$ Center for Research on Ageing, "G. d'Annunzio" University Foundation, Chieti, Italy

Full list of author information is available at the end of the article
}

Human infection, mainly acquired from dogs, has however only recently been reported. The first case of human infection by S. pseudintermedius was described in 2006 by Van Hoovels et al. [3] causing endocarditis after the implantation of a cardioverter-defribrillator device (ICD). Since then, human infections have been reported sporadically, including surgical site infections, rhinosinusitis, and catheter associated bacteremia [4-6].

The last published case of human S. pseudintermedius infection, the second case involving a methicillin-resistant strain, recently arrived at our observation [7]. A 65-yearold male patient who received an allogeneic bone marrow

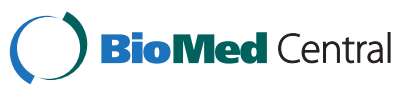

(c) 2015 Pompilio et al.; licensee BioMed Central. This is an Open Access article distributed under the terms of the Creative Commons Attribution License (http://creativecommons.org/licenses/by/4.0), which permits unrestricted use, distribution, and reproduction in any medium, provided the original work is properly credited. The Creative Commons Public Domain Dedication waiver (http://creativecommons.org/publicdomain/zero/1.0/) applies to the data made available in this article, unless otherwise stated. 
transplant for chronic lymphoblastic leukemia, was admitted to the "Spirito Santo" Hospital of Pescara (Italy), because of a wound infection. The lesion, secondary to the chronic Graft-versus-Host Disease (GvHD) that complicated the transplant, was located in the periumbilical region and showed two different purulent discharges that grew S. pseudintermedius, namely strain DSM (Deutsche Sammlung von Mikroorganismen und Zellkulturen, $\mathrm{GmbH}$ ) 25713. The patient had a history of close association with a companion dog, as well as farm cows.

Knowledge of the pathogenesis of S. pseudintermedius remains yet limited. It is known that veterinary strains are able to produce numerous virulence factors, including $\beta$-hemolysin, clumping factor, coagulase, DNase, protein A, lipase, leukotoxin, exfoliative toxin, and enterotoxins $[8,9]$. Furthermore, S. pseudintermedius methicillinresistant strains have recently emerged as a major challenge, for veterinary dermatologists in particular, owing to their extensive multidrug resistance and their behavior as nosocomial pathogens [10].

Biofilm formation is considered to be one of the most important virulence factors in staphylococci, especially for Staphylococcus aureus and Staphylococcus epidermidis, as it allows them to adhere to tissues and indwelling medical devices [11].

A biofilm is a structured consortium of bacteria adhered to a substratum and embedded in a self-produced extracellular polymer substance (EPS) consisting of polysaccharide, protein and DNA. Bacterial biofilms are of clinical relevance since they confer resistance to antibiotics and disinfectants, as well as resistance to phagocytosis and the host immune system generally, all factors promoting chronic infections.

Biofilm forming ability of veterinary S. pseudintermedius isolates has been reported, although not extensively $[8,12-14]$. Most strains were identified as biofilmproducers [14], although isolates belonging to the most frequent sequence type observed in Europe, ST71, had a significantly greater ability to produce biofilm [12], with strains from canine conjunctivitis also demonstrating increased production [8].

Although the presence of virulence factors such as DNase, $\beta$-hemolysin, coagulase, and leukotoxins was also observed in S. pseudintermedius strains isolated from humans $[3,5]$, to the best of our knowledge the potential for biofilm formation of these strains has yet to be investigated.

Therefore, the present work was aimed at assessing, for the first time in literature, the ability of a human $S$. pseudintermedius strain to form biofilm, as well as its pathogenic potential. In this regard, biofilm formation by the wound isolate $S$. pseudintermedius strain DSM 25713 was evaluated under different conditions relevant for wound site (i.e. different concentrations of serum, tested as free or substratum-adsorbed; and different $\mathrm{pH}$ values suggestive of acid, neutral and basic wound environments), and in the presence of eight antibiotics tested at both sub-inhibitory and bactericidal concentrations against biofilm formation and preformed (mature) biofilms, respectively. Biofilm architecture and kinetics of formation were further studied using both scanning electron and confocal laser scanning microscopy.

Overall, our results clearly show that S. pseudintermedius strain DSM 25713 is able to form a biofilm ultrastructurally complex that is inherently resistant to antibiotics, confirming the pathogenic potential of this bacterium to cause human disease.

\section{Materials and methods}

\section{Bacterial strain and growth conditions}

The strain S. pseudintermedius DSM 25713 was isolated from a wound of a haematologic patient recently admitted to "Santo Spirito" Hospital in Pescara, Italy [7]. Strain identification was carried out using biochemical tests (API system; bioMerieux, Marcy l'Etoile, France), and confirmed by $16 \mathrm{~S}$ RNA sequencing. Bacterial stocks were stored at $-80{ }^{\circ} \mathrm{C}$ until their use, when they were thawed, inoculated into Trypticase Soy broth (TSB; Oxoid SpA, Garbagnate M.se, Italy), and incubated at $37{ }^{\circ} \mathrm{C}$ for $24 \mathrm{~h}$. An aliquot was then plated twice on Mueller-Hinton agar (MHA; Oxoid SpA) to check for the purity of the culture. A standardized suspension of $1.0 \times 10^{8} \mathrm{CFU} / \mathrm{mL}$ (corresponding to OD of 1.0 at $550 \mathrm{~nm}$ ) was prepared in TSB and used immediately for all experiments.

\section{Standardization and optimization of S. pseudintermedius biofilm growth on polystyrene}

Since the optimal conditions for S. pseudintermedius biofilm formation on polystyrene surfaces are not known, preliminary experiments were carried out to optimize and standardize the in vitro model for biofilm formation. The following basic parameters for biofilm growth were considered for optimization: i) inoculum size (suspensions at $10^{5}, 10^{6}$, and $10^{7} \mathrm{CFU} / \mathrm{ml}$ were prepared starting from standardized inoculum); ii) dynamic (cultures were incubated under agitation at $200 \mathrm{rpm}$ ) (IKA agitator KS 260; IKA, Milan, Italy) or static conditions; and iii) incubation time $(24,48$, and $72 \mathrm{~h})$.

Based on our results, an inoculum size of $10^{7} \mathrm{CFU} / \mathrm{ml}$, and static incubation were used for S. pseudintermedius biofilm formation, while susceptibility to antibiotics was tested by exposing $48 \mathrm{~h}$-biofilms to antibiotic for a further $24 \mathrm{~h}$.

\section{Quantitative measurement of static biofilms}

In brief, $200 \mu \mathrm{l}$ of the standardized inoculum at desired concentration prepared in TSB (Oxoid SpA) was added aseptically to each well of a 96-well polystyrene tissue 
culture plate (Falcon BD; Becton, Dickinson and Company, Milan, Italy), and incubated at $37{ }^{\circ} \mathrm{C}$ under static conditions. Wells that only contained TSB were considered as controls. At the end of the incubation, spent medium was discarded and each well was washed twice with PBS (pH 7.2) (Sigma-Aldrich Srl, Milan, Italy) to remove non-adherent cells. Biofilm formation was then assessed by crystal violet assay or viable cell count. i) Crystal violet microtiter plate assay [15]. Biofilm samples were fixed by incubating plates at $60{ }^{\circ} \mathrm{C}$ for $1 \mathrm{~h}$, then stained for 5 min with $200 \mu$ l Hucker-modified crystal violet [16]. Excess stain was rinsed off with running tap water, and then the plates were air-dried. Crystal violet was extracted by exposure at room temperature for $15 \mathrm{~min}$ to $200 \mu \mathrm{l}$ glacial acetic acid $33 \%$ (Sigma-Aldrich), and biofilm biomass (including adherent bacteria and EPS) was then assessed by measuring the optical density at $492 \mathrm{~nm}\left(\mathrm{OD}_{492}\right)$ (SpectraMax 190; Molecular Devices, Sunnyvale, CA, USA). ii) Total viable cell count. In each well, the biofilm sample was scraped by using a pipette tip after 5-min exposure to $200 \mu \mathrm{l}$ trypsin-EDTA $0.25 \%$ (Sigma-Aldrich), then resuspended in sterile PBS by vortexing. Serial 10-fold dilutions of each sample were prepared in sterile PBS and $100 \mu \mathrm{l}$ of each dilution was plated on MHA and incubated at $37{ }^{\circ} \mathrm{C}$ for $24 \mathrm{~h}$. Colonies were counted to estimate biofilm viability.

\section{Continuous flow through biofilm}

Biofilm was allowed to form in a polycarbonate flow through chamber (The Technical University of Denmark, Lyngby, Denmark) for microscopic studies [17]. The flow cell is composed of three parallel channels in perspex (poly[methyl methacrylate]), covered with a no. $124 \times$ $50 \mathrm{~mm}$ glass coverslip which serves as the biofilm substratum. Each channel has a dimension (length $\times$ width $\times$ height) of $40 \times 4 \times 4 \mathrm{~mm}$ and was cleaned with $96 \%(\mathrm{v} / \mathrm{v})$ ethanol prior to use.

In brief, the chamber was inoculated with standardized inoculum diluted in TSB at $5 \times 10^{5} \mathrm{CFU} / \mathrm{ml}$, then inverted to allow microorganisms to attach for $3 \mathrm{~h}$, under static conditions, at $37^{\circ} \mathrm{C}$. The flow cell was then placed upright and the pump started with a TSB flow rate of $0.5 \mathrm{ml} / \mathrm{min}$. Biofilm was allowed to form for $24 \mathrm{~h}$ at $37{ }^{\circ} \mathrm{C}$, then washed with PBS ( $2 \mathrm{~min}$ at $0.5 \mathrm{ml} / \mathrm{min}$ ), and finally observed by a confocal laser scanning microscope.

\section{Time course of biofilm formation}

Biofilms were allowed to form in each well of a 24-well flat-bottom polystyrene tissue-treated microtiter plate (BD Company), as described above. At selected times (30 min, 1, 2, 4, 8, 24, 48, and $72 \mathrm{~h}$ of incubation) biofilm viability was assessed by viable colony count as described above. In a parallel series of experiments, wells were broken and fragments representative of each time point were observed by scanning electron microscopy.

\section{Effect of human serum and $\mathrm{pH}$ on biofilm formation}

Serum for testing was pooled from multiple samples. Serum samples were collected from 30 blood donors, which were selected based on their health status as nonsmokers with no other known current diseases, and because they were not on any medications. The serum samples were then pooled, aliquoted, and stored at $-20{ }^{\circ} \mathrm{C}$ until use. Since it was observed that albumin and total protein levels were significantly higher in serum than in wound fluid [18], serum was tested against biofilm formation at different dilutions (1:2, 1:10, and 1:100) prepared in TSB. Serum was tested both as free (soluble) and adhered to polystyrene. In the latter case, serum-coated microplates were prepared immediately before use. In brief, $200 \mu \mathrm{l}$ of serum was added to each well of a 96-well tissue culture plates (BD Company), incubated for $2 \mathrm{~h}$ at $37^{\circ} \mathrm{C}$, then washed by PBS to remove excess serum.

The effect of $\mathrm{pH}$ and serum on S. pseudintermedius biofilm formation was simultaneously assessed. To this end, 96-well microtiter plates containing free or adsorbed serum were inoculated with the standardized inoculum prepared in TSB that was previously corrected at different $\mathrm{pH}$ values $(5.5,7.1$, and 8.7$)$ by using $\mathrm{HCl}$ or $\mathrm{NaOH} 1 \mathrm{M}$ solution, then incubated at $37{ }^{\circ} \mathrm{C}$ for $24 \mathrm{~h}$. Biofilm biomass levels were then spectrophotometrically measured as described above.

\section{Susceptibility assays}

Susceptibility of S. pseudintermedius strain DSM 25713 to chloramphenicol, gentamicin, cefoxitin, linezolid, rifampicin, vancomycin, tetracycline, and tigecycline (all were purchased, as reference powders, from Sigma-Aldrich) was determined by microdilution technique, in accordance with CLSI M100-S20 guidelines [19]. MIC was calculated as the lowest concentration of the test agent that completely inhibited visible growth. MBC was evaluated as the lowest concentration of the test agent killing of at least $99.99 \%$ of the original inoculum. E. faecalis ATCC29212 and $E$. coli ATCC25922 were used as reference strains.

\section{Antibiotic activity against biofilm formation}

In each well of a 96-well flat-bottom polystyrene tissueculture microtiter plate (Becton, Dickinson and Company), $5 \mu \mathrm{l}$ of a standardized inoculum $\left(1-5 \times 10^{7} \mathrm{CFU} /\right.$ $\mathrm{ml}$ ) were added to $100 \mu \mathrm{l}$ of cation-adjusted MuellerHinton broth (CAMHB; Oxoid SpA) containing antibiotic at $1 / 2 \times, 1 / 4 \times$, and $1 / 8 \times \mathrm{MIC}$. After incubation at $37^{\circ} \mathrm{C}$ for $24 \mathrm{~h}$, non-adherent bacteria were removed by washing twice with $100 \mu \mathrm{l}$ sterile PBS, then biofilm levels were spectrophotometrically measured as described above. 


\section{Antibiotic activity against preformed biofilms}

The activity of antibiotics against 48 h-old biofilms was assessed by viable colony count. Biofilms were allowed to form in each well of a 96-well flat-bottom polystyrene tissue-treated microtiter plate (Becton, Dickinson and Company), as described above. Following 48 h-incubation, biofilms samples were washed twice with PBS, then exposed to $200 \mu \mathrm{l}$ of drug-containing CAMHB (prepared at $1,2,4,8,16,32,64$, and $128 \times \mathrm{MIC})$. After incubation at $37{ }^{\circ} \mathrm{C}$ for $24 \mathrm{~h}$, non-adherent bacteria were removed by washing twice with $200 \mu \mathrm{l}$ sterile PBS, and biofilm samples were scraped as described above. Cell suspension was then vortexed for $1 \mathrm{~min}$ to break up bacterial clumps. Bacterial counts were performed by plating serial 10-fold dilutions of this suspension on MHA plates. Control biofilm samples were not exposed to antibiotics. Minimum Biofilm Eradication Concentration (MBEC) was calculated as the minimum concentration of tested antibiotic able to eradicate preformed biofilm.

\section{Microscopic analyses}

Kinetics of biofilm formation by $S$. pseudintermedius strain DSM 25713 and its architecture were assessed by scanning electron microscopy (SEM) and environmentalSEM (ESEM), respectively. The effects of exposure to several gentamicin concentrations as well as the ultrastructure of biofilm formed under dynamic incubation were evaluated by confocal laser scanning microscopy (CLSM). i) SEM and ESEM assays. Biofilm formation kinetics in TSB was monitored - under static conditions, without serum, at $37^{\circ} \mathrm{C}$, and at $\mathrm{pH} 7.1$ - in $35 \mathrm{~mm}$-tissue culture polystyrene dish (Becton, Dickinson and Company) at different time periods (30 min, 1, 2, 4, 8, 24, 48, and $72 \mathrm{~h}$ ). Samples were then fixed in a mixture of $2 \%$ paraformaldehyde (Electron Microscopy Sciences, Hatfield, PA, USA) + $2 \%$ glutaraldehyde (Sigma-Aldrich) [vol/ vol] in $0.15 \mathrm{M}$ sodium cacodylate buffer ( $\mathrm{pH} 7.4$; Fluka), with $0.1 \%$ alcian blue (Sigma-Aldrich). Samples were post-fixed for $90 \mathrm{~min}$ at room temperature in $1 \%$ OsO4 [vol/vol] (Electron Microscopy Sciences) in $0.15 \mathrm{M}$ cacodylate buffer, then dehydrated in an ascending ethanol series (50, 70, 80, 95, and twice $100 \%$; $10 \mathrm{~min} / \mathrm{each})$, dried for $30 \mathrm{~min}$ with hexamethyldisilazane (Polysciences Inc., Warrington, PA, USA), and finally air-dried. Specimens were coated with gold-palladium by Polaron E5100 II (Polaron Instruments Inc.), and then observed with a Philips XL30CP scanning electron microscope in the high-vacuum mode at $15 \mathrm{kV}$. In a parallel experiment, a 72 h-old biofilm sample was fixed and post-fixed as described above, and directly observed using a Zeiss EVO (Carl Zeiss SpA, Arese, Milan, Italy). ii) CLSM assay. Briefly, 48 h-biofilms were allowed to grow on polystyrene as described for SEM analysis, then exposed to gentamicin at different concentrations (from $1 \mathrm{x}$ to $128 \mathrm{xMIC}$ ) for a further $24 \mathrm{~h}$. Untreated biofilms were used as controls. In a parallel series of experiments, biofilm was allowed to grow under dynamic conditions in a flow cell system in the absence of antibiotics, as described above. Both static and flow cell biofilms were stained with Live/Dead BacLight kit (Molecular Probes Inc., Eugene, USA) and Concanavalin A (Alexa Fluor 647 coniugate; Molecular Probes Inc.). Static biofilm samples formed on polystyrene were placed in an Attofluor cell-chamber (Molecular Probes Inc.) before observation. CLSM analysis was performed with an LSM 510 META laser scanning microscope attached to an Axioplan II microscope (Zeiss Italia, Arese, Milan, Italy). Depth measurements were taken at regular intervals across the width of the device. To determine biofilm structure, a Z-series of 25 optical planes at $x y$ resolution of $512 \times 512$ pixel $(68.4 \times$ $68.4 \mu \mathrm{m})$ with a thickness of $1.00 \mu \mathrm{m}$ was taken throughout the biofilm. Both SEM and CLSM representative images were captured and processed for display using Photoshop (Adobe Systems Inc., San Jose, California) software.

\section{Statistical analysis and biofilm interpretative criteria}

All experiments were carried out at least in triplicate and repeated at least on two different occasions. Differences were assessed by unpaired- $t$ test (standardization of in vitro model of biofilm formation), ANOVA + Newman-Keuls multiple comparison post-test (effect of serum and $\mathrm{pH}$ both on biofilm formation and bacterial growth), chi-square test (percentage of reduction of both biofilm biomass formation and biofilm viability), or Kruskall-Wallis + Dunn's multiple comparison post-test (kinetic of biofilm formation). Statistical analysis of results was conducted with GraphPad Prism version 6.00 (GraphPad software Inc.; San Diego, CA, USA), considering as statistically significant a $p$ value of $<0.05$.

The low cut-off value for biofilm formation was represented by 3 SDs above the mean $\mathrm{OD}_{492}$ of control wells (containing bacteria-free medium) [20].

To evaluate the effect of serum and $\mathrm{pH}$ on biofilm formation, biofilm levels were normalized for bacterial growth by calculating the specific biofilm formation (SBF) index: $\mathrm{SBF}=\left(\mathrm{OD}_{\text {biofilm }}-\mathrm{OD}_{\mathrm{NC}}\right) / \mathrm{OD}_{\text {growth }}$ in which $\mathrm{OD}_{\text {biofilm }}$ is the $\mathrm{OD}_{492}$ of the stained biofilm, $\mathrm{OD}_{\mathrm{NC}}$ is the $\mathrm{OD}_{492}$ of the stained negative control wells (to eliminate unspecific or abiotic OD values), and $\mathrm{OD}_{\text {growth }}$ is the $\mathrm{OD}_{600}$ of cells grown in broth.

The percentage of inhibition of biofilm formation by antibiotics tested at sub-inhibitory concentrations was calculated as follows: $\left(1-\mathrm{OD}_{\exp } / \mathrm{OD}_{\mathrm{UC}}\right) \times 100$ in which $\mathrm{OD}_{\text {exp }}$ is the $\mathrm{OD}_{492}$ of the stained antibiotic-exposed biofilm, and $\mathrm{OD}_{\mathrm{UC}}$ is the $\mathrm{OD}_{492}$ of the stained untreated control biofilm. 


\section{Results}

Standardization and optimization of biofilm growth

S. pseudintermedius strain DSM 25713 biofilm growth on polystyrene, as assessed by crystal violet assay, under different experimental conditions is summarized in Fig. 1. A similar trend was observed, regardless of the inoculum size considered $\left(10^{5}, 10^{6}\right.$ or $\left.10^{7} \mathrm{CFU} / \mathrm{ml}\right)$. Specifically, although significantly higher $(p<0.001)$ biofilm formation occurred following $24 \mathrm{~h}$-incubation under dynamic conditions compared to static ones, we observed an opposing trend at 48 and 72 h-incubation $(p<0.001)$. Maximum biofilm amount was produced at $10^{7} \mathrm{CFU} / \mathrm{ml}$ after $72 \mathrm{~h}$ of incubation, while no statistically significant differences were found among the tested inoculum sizes $\left(\mathrm{OD}_{492}: 2.698,2.423\right.$, and 2.491 , at $10^{7}, 10^{6}$, and $10^{5} \mathrm{CFU} /$ $\mathrm{ml}$, respectively; $p>0.05$ ). Therefore, an inoculum size of $10^{7} \mathrm{CFU} / \mathrm{ml}$, and static incubation were used for optimal biofilm formation by S. pseudintermedius on a polystyrene surface. Since no statistically significant differences in biofilm biomass formation were observed between 48 and $72 \mathrm{~h}$ of incubation, we choose to allow the biofilm to grow for $48 \mathrm{~h}$ and then expose it to antibiotics for another $24 \mathrm{~h}$ in the evaluation of antibiotic activity against preformed biofilm.

\section{Effects of serum and $\mathrm{pH}$ on biofilm formation}

The combined effects of different serum concentrations and $\mathrm{pH}$ values on biofilm formation by S. pseudintermedius strain DSM 25713 are summarized in Fig. 2.

In the absence of serum, biofilm formation at $\mathrm{pH} 7.1$ was significantly higher than that obtained at $\mathrm{pH} 5.5$ or 8.7 (SBF: $5.33 \pm 1.06$ vs $2.82 \pm 1.25$ and $3.10 \pm 1.05$, respectively; $p<0.05$ ) (Fig. 2a). Furthermore, considering the criteria proposed by Stepanovic et al. [20] S. pseudintermedius strain DSM 25713 continuously demonstrated a strong capacity to produce biofilm (mean $\mathrm{OD}_{492}>0.280$ ), regardless of the $\mathrm{pH}$ value considered.

In the presence of serum the ability to form biofilm was significantly affected, regardless of the $\mathrm{pH}$ value tested. Specifically, the amount of biofilm was reduced compared to the control, with ranges of 45.3-87.5\%, 74.3-95.5\%, and $21.9-96.5 \%$ at $\mathrm{pH}$ values of $5.5,7.1$, and 8.7 , respectively (Fig. 2a).

Polystyrene pre-treatment with serum significantly reduced biofilm formation under acidic conditions, but only in the presence of 1:2 and 1:10 serum (reduction vs control: 59.4 and $78.5 \%$, respectively), and neutral $\mathrm{pH}$ (82.7-88.3 \%). At pH 8.7, coating with serum did not significantly reduce biofilm formation (Fig. 2a). The antibiofilm effect was shown to be dependent only upon concentration levels in the case of free serum, regardless of the $\mathrm{pH}$ value considered.

\section{$10^{7} \mathrm{cfu} / \mathrm{mL}$}

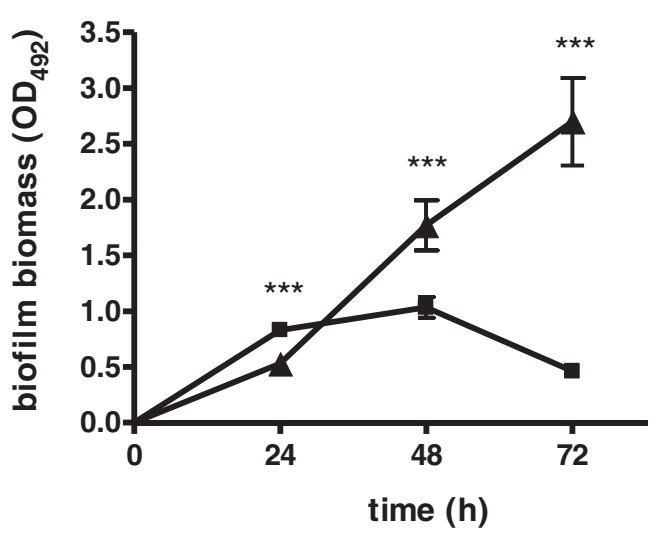

$10^{6} \mathrm{cfu} / \mathrm{mL}$

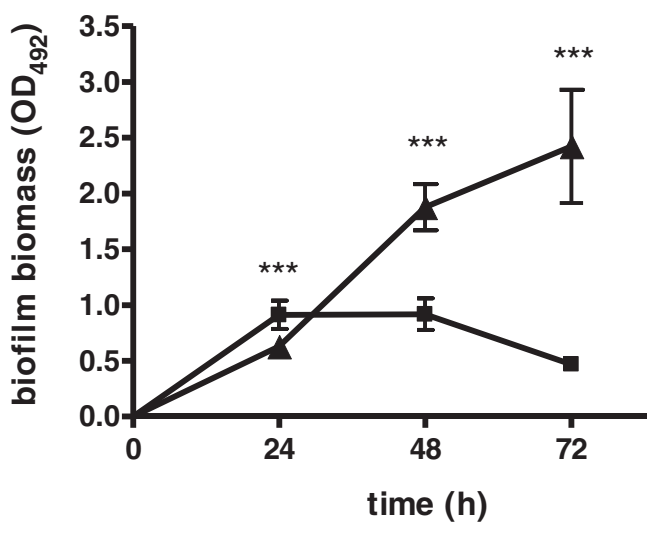

$10^{5} \mathrm{cfu} / \mathrm{mL}$

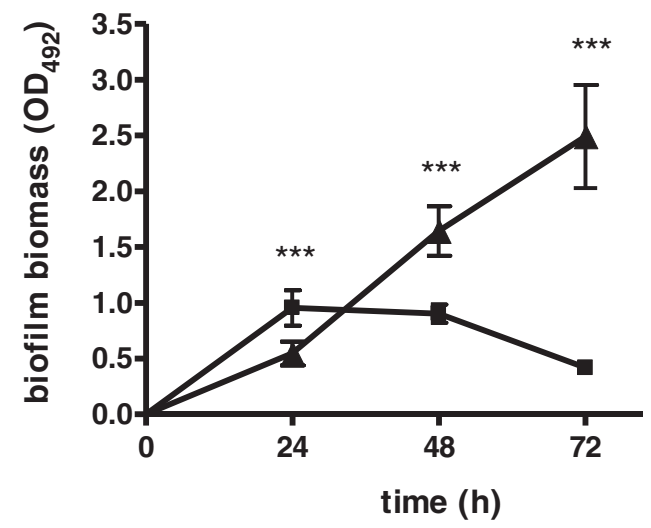

Fig. 1 Standardization of experimental conditions for biofilm formation by S. pseudintermedius strain DSM 25713 on polystyrene surface. Effect of dynamic (filled squares) or static (filled triangles) incubation, incubation time $(24,48$, and 72 h), and inoculum concentration $\left(10^{5}, 10^{6}\right.$, and $\left.10^{7} \mathrm{CFU} / \mathrm{mL}\right)$ on biofilm biomass formation, as assessed by spectrophotometric assay. Values are means \pm SDs $(n=6)$. ${ }^{* * *} p<0.001$, dynamic vs static, unpaired- $t$ test 
(a)

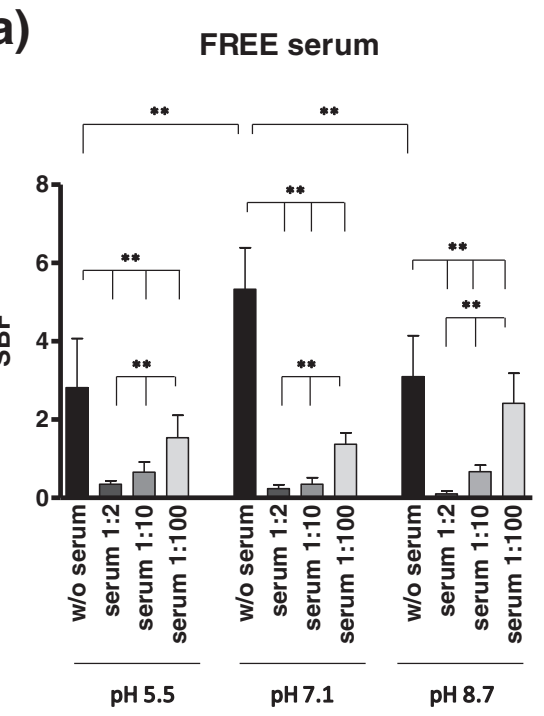

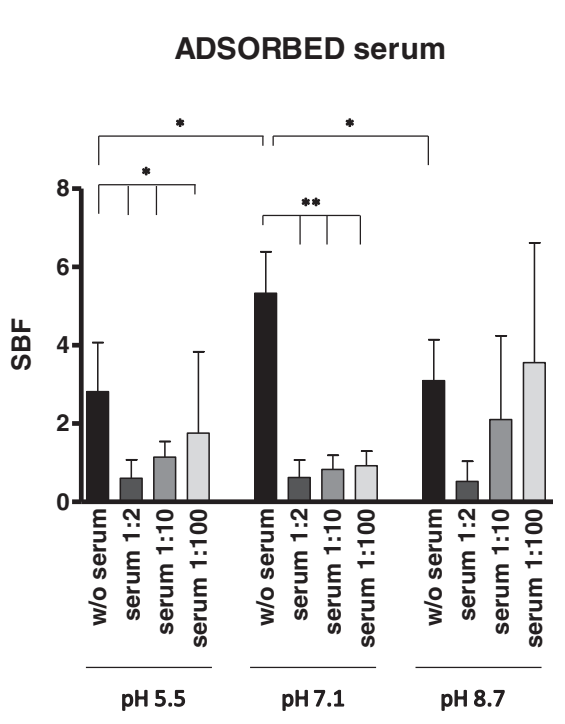

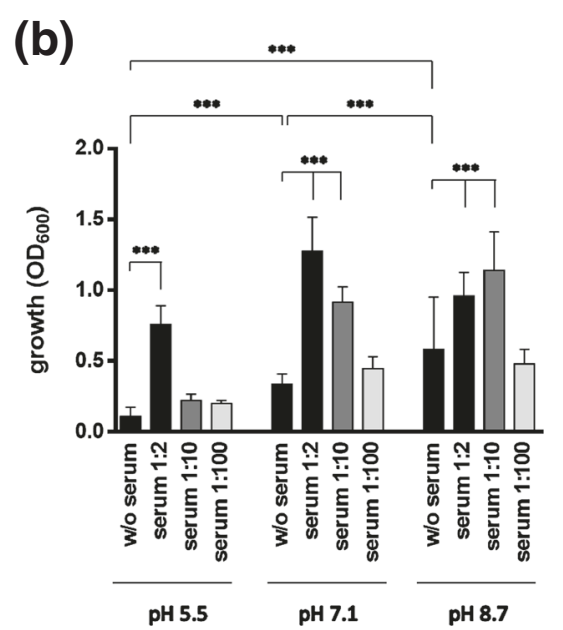

Fig. 2 Effect of serum and pH on biofilm formation and growth by S. pseudintermedius strain DSM 25713. (a) Serum was tested against biofilm formation at various dilutions (1:2, 1:10, and 1:100), as free or adsorbed to polystyrene, under different pH (5.5, 7.1, and 8.7). Control wells contained bacteria but not serum. Biofilm biomass amount was measured by crystal violet assay, then normalized on bacterial growth by calculating the specific biofilm formation (SBF) index (see Materials and Methods). (b) The effect of free serum against bacterial growth was assessed by measuring $\mathrm{OD}_{600}$ of cell grown in broth following 24 h-incubation. Results are means $+\operatorname{SDs}(n=9) .{ }^{*} p<0.05$, ${ }^{* *} p<0.01$, and ${ }^{* * *} p<0.001$, ANOVA + Newman-Keuls multiple comparison post-test

As shown by the comparative evaluation of $\mathrm{OD}_{600}$ values of supernatant culture that were measured following $24 \mathrm{~h}$-incubation, planktonic growth of $S$. pseudintermedius strain DSM 25713 was significantly enhanced in the presence of serum. This effect was more relevant at $\mathrm{pH} 7.1$ and 8.7, when serum was effective at both 1:2 and 1:10 (Fig. 2b). In the absence of serum, S. pseudintermedius strain DSM 25713 growth was $\mathrm{pH}$-dependent, with maximum result at $\mathrm{pH} 8.7$ $\left(\mathrm{OD}_{600}\right.$, mean \pm SD: $0.583 \pm 0.370$ vs $0.337 \pm 0.071$ and $0.107 \pm 0.067$ at $\mathrm{pH} 8.7,7.1$ and 5.5, respectively; $p<$ $0.001)$.

\section{Susceptibility of planktonic cells to antibiotics}

In vitro susceptibility of $S$. pseudintermedius strain DSM 25713 planktonic cells to chloramphenicol, gentamicin, cefoxitin, linezolid, rifampicin, tigecycline, tetracycline, and vancomycin is summarized in Table 1.

MIC values showed that rifampicin is the most active antibiotic among those tested (MIC: $0.03 \mu \mathrm{g} / \mathrm{ml}$ ). On the contrary, cefoxitin and chloramphenicol were the least active drugs (MIC: 16 and $32 \mu \mathrm{g} / \mathrm{ml}$, respectively). The comparative evaluation of MIC and MBC values showed bactericidal activity only for cefoxitin, gentamicin, and vancomycin $(\mathrm{MBC} / \mathrm{MIC}<4)$. 
Table 1 In vitro antibiotic susceptibility of planktonic and biofilm S. pseudintermedius strain DSM 25713 cells. MIC, Minimum Inhibitory Concentration; MBC, Minimum Bactericidal Concentration; $\mathrm{MBEC}_{50}$ and $\mathrm{MBEC}_{90}$, Minimum Concentrations Eradicating respectively $50 \%$ and $90 \%$ of Biofilm viability, compared to untreated controls (100\% viability). Assays were performed in triplicate and repeated on two different occasions $(n=6)$. Values are $m g / L$

\begin{tabular}{llllll}
\hline Antibiotics & \multicolumn{2}{l}{ Planktonic cells } & \multicolumn{2}{l}{ Biofilm cells } & C $_{\max }{ }^{a}$ \\
& MIC & MBC & MBEC $_{50}$ & MBEC $_{90}$ & \\
\hline Chloramphenicol & 32 & 256 & 128 & 4,096 & $16.9[49]$ \\
Gentamicin & 0.5 & 0.5 & 32 & 32 & $5-12[50]$ \\
Cefoxitin & 16 & 32 & 16 & 1,024 & $20[51]$ \\
Linezolid & 4 & 32 & 4 & 1,024 & $21.2[52]$ \\
Rifampicin & 0.03 & 0.5 & 0.03 & 0.06 & $10[53]$ \\
Tigecycline & 0.5 & 8 & 0.5 & 64 & $0.25-2.8[54]$ \\
Tetracycline & 0.5 & 8 & 0.5 & 64 & $2[55]$ \\
Vancomycin & 2 & 2 & 16 & 32 & $25[56]$ \\
\hline
\end{tabular}

${ }^{a}$ Maximum concentration of drug in serum; references are shown in parentheses

\section{Effects of subinhibitory antibiotic concentrations on biofilm formation}

The effects of antibiotics tested at sub-inhibitory concentrations $(1 / 2 \mathrm{x}, 1 / 4 \mathrm{x}$, and $1 / 8 \mathrm{xMIC})$ against biofilm formation are shown in Fig. 3.

Generally, sub-inhibitory concentrations caused a significant reduction in the formation of biofilm in a dosedependent manner, although striking differences were observed among the antibiotics tested.

Cefoxitin proved to be the most active antibiotic since at $1 / 8 \mathrm{xMIC}$ it provoked a reduction in biofilm formation of S. pseudintermedius strain DSM 25713 that was significantly higher than other antibiotics (\% biofilm biomass vs control, $13.5 \pm 4.9$ ). Chloramphenicol, gentamicin, linezolid, rifampicin and tigecycline also caused a significant reduction in biomass regardless of the concentrations tested. On the contrary, tetracycline and vancomycin were the least active against antibiotics, showing an inability to affect biofilm formation at concentrations equal to $1 /$ $8 \mathrm{xMIC}$ or both at $1 / 4 \mathrm{x}$ and $1 / 8 \mathrm{xMIC}$, respectively.

\section{Effects of antibiotics on preformed biofilms}

The activity of antibiotics, tested at concentrations equal to or a multiple of MIC, on mature biofilms is summarized in Table 1 and Fig. 4.

The comparative evaluation between MIC and MBEC values indicated that rifampicin is the most active antibiotic against preformed biofilms $\left(\mathrm{MBEC}_{50}\right.$ and $\mathrm{MBEC}_{90}$ : $1 \mathrm{x}$ and $2 \mathrm{xMIC}$, respectively) (Table 1 ). Other antibiotics showed a reduced activity, although at different extents. In particular, vancomycin showed $\mathrm{MBEC}_{50}$ and $\mathrm{MBEC}_{90}$ of $8 \mathrm{x}$ and 16xMIC, respectively, followed by cefoxitin $\left(\mathrm{MBEC}_{50}\right.$ and $\mathrm{MBEC}_{90}: 1 \mathrm{x}$ and $64 \mathrm{xMIC}$, respectively). Chloramphenicol MBEC $_{50}$ and MBEC $_{90}$ : $4 \mathrm{x}$ and $128 \mathrm{x}$ $\mathrm{MIC}$, respectively), linezolid, tetracycline and tigecycline $\left(\mathrm{MBEC}_{50}\right.$ and $\mathrm{MBEC}_{90}: 1 \mathrm{x}$ and $>128 \mathrm{xMIC}$, respectively) showed comparable activity. Gentamicin was the least active among the antibiotics tested $\left(\mathrm{MBEC}_{50}\right.$ and MBEC $_{90}$ : $64 \mathrm{xMIC}$ ), even stimulating the production of significantly higher biofilm amounts at $1 \mathrm{x}$ and $2 \mathrm{xMIC}$, compared to controls (Fig. 4). All antibiotics exhibited a dose-dependent effect, except for linezolid, rifampicin, and tigecycline. Importantly, none of the antibiotics studied were able to eradicate mature biofilms at the concentrations tested (Fig. 4).

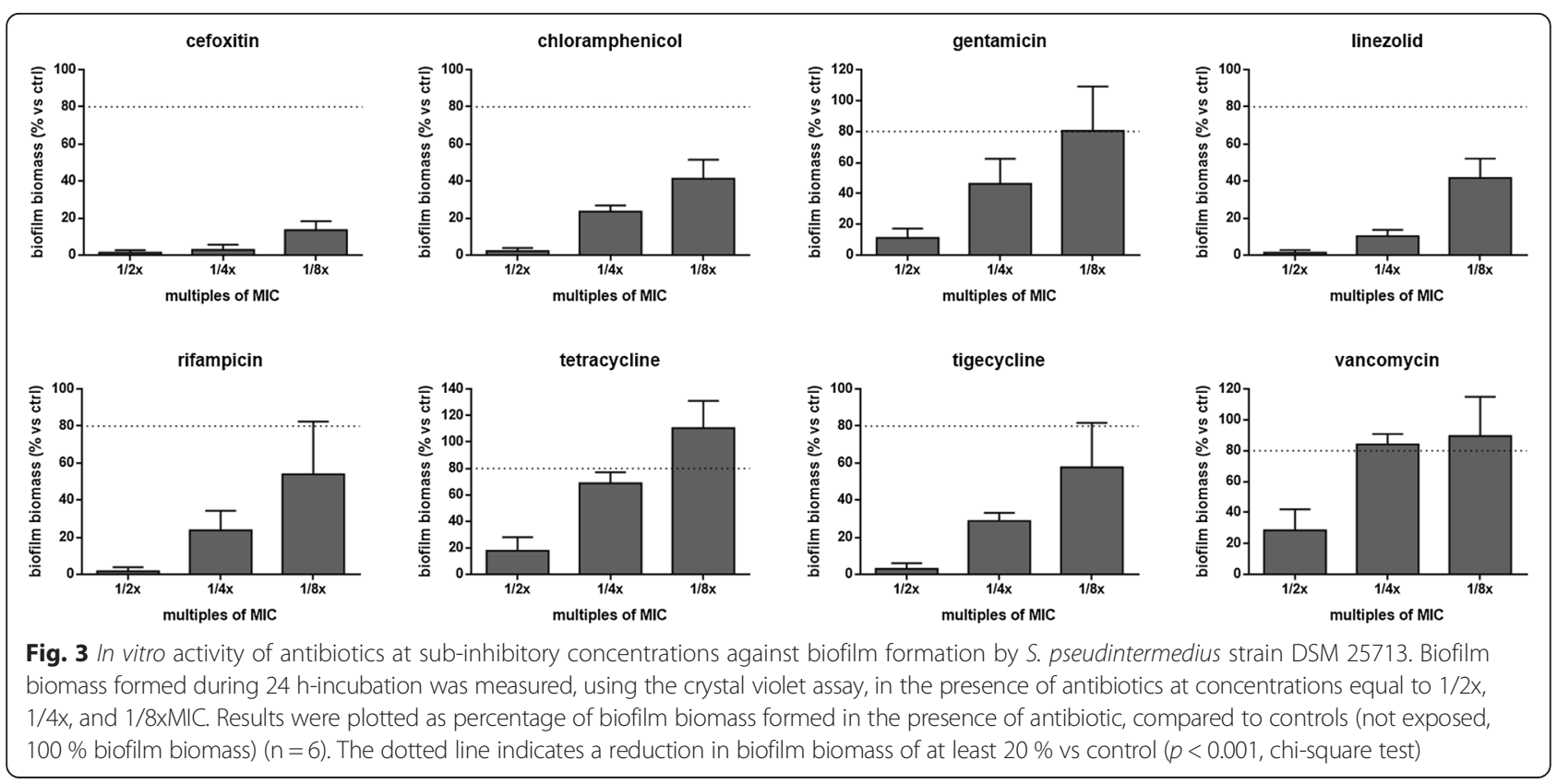




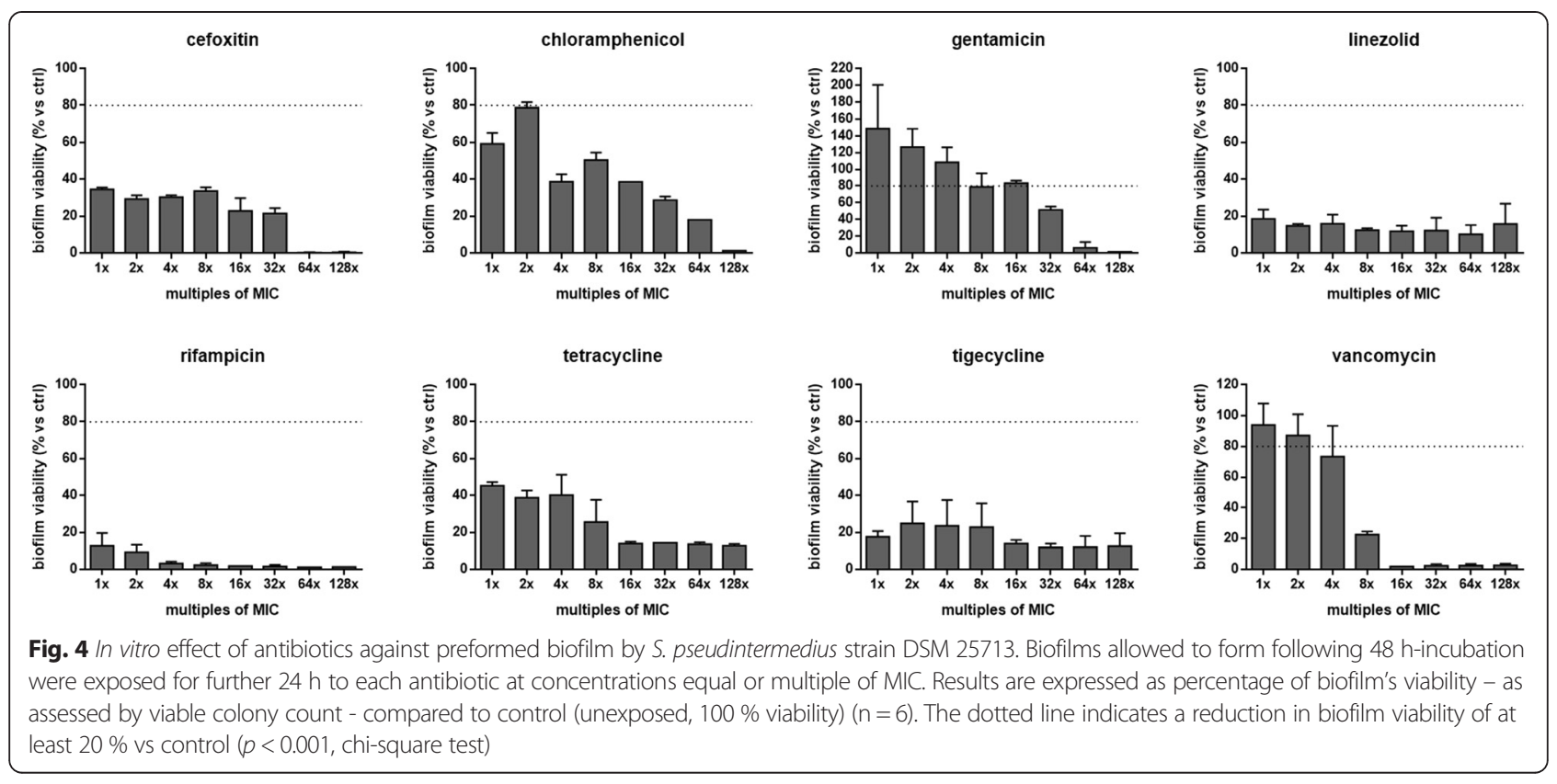

In consideration of the concentrations corresponding to MBEC $_{90}$ values, rifampicin was confirmed to be the most active antibiotic $\left(\mathrm{MBEC}_{90}: 0.06 \mu \mathrm{g} / \mathrm{ml}\right)$, followed by vancomycin and gentamicin $\left(\mathrm{MBEC}_{90}: 32 \mu \mathrm{g} / \mathrm{ml}\right)$, while chloramphenicol was the least effective (MBEC $90: 4,096 \mu \mathrm{g} / \mathrm{ml}$ ) (Table 1).

\section{Microscopic analysis of biofilms formed under static and dynamic conditions}

Representative CLSM images of biofilm formed by $S$. pseudintermedius strain DSM 25713 are shown in Fig. 5. Under static incubation, S. pseudintermedius is able to form a dense biofilm with "mushroom-like" architecture consisting of aggregates and microcolonies that almost completely cover the polystyrene surface. The biofilm formed in flow cell chamber, under dynamic conditions, was shown to be significantly more complex, in terms of thickness and cellularity, compared to the biofilm formed under static incubation (mean thickness, 25.4 vs $14.2 \mu \mathrm{m}$, respectively; $p<0.05$ ) (Figs. 5a-b).

Corresponding to the results obtained with the viable cell count testing, there were variations in biofilm amount and morphology observed in a dose dependent response to gentamycin. At 1xMIC, biofilm amount was increased, while at 8xMIC and above, there were alterations in the three-dimensional structure of the biofilms seen, and some disruption of established biofilms.

SEM analysis was performed to monitor the biofilm formation kinetics throughout $72 \mathrm{~h}$ of incubation, and to analyze the morphological characteristics of biofilm (Fig. 6). After only $30 \mathrm{~min}$, single cocci randomly adhered to polystyrene (adhesion phase). After $4 \mathrm{~h}$, early biofilm appeared as small microcolonies, consisting mainly of clustered cells without any evidence of EPS (Fig. 6b). During the maturation phase ( 8 to $72 \mathrm{~h}$ ), microcolonies dimensionally increased, covering most of the surface (Figs. 6c-f). In particular, the addition of alcian blue to the fixative solution revealed a significant production of EPS after $48 \mathrm{~h}$, appearing as an extensive network of filaments. EPS covered most of the surface, surrounded biofilm cells and bridged these to the substratum (Figs. $6 \mathrm{~g}$-h).

The kinetics of biofilm formation by S. pseudintermedius strain DSM 25713 on the surface of polystyrene wells over $72 \mathrm{~h}$ is shown in Fig. 6i. Viable counts confirmed the findings obtained during SEM analysis. In particular, bacteria were shown to attach rapidly, within $1 \mathrm{~h}$ of incubation (median: $1.5 \times 10^{5} \mathrm{CFU} /$ well), then the biofilm formation increased over time up to $48 \mathrm{~h}$ (median: $1.6 \times 10^{8} \mathrm{CFU} /$ well).

We also performed ESEM to obtain a deeper and more realistic view of the $3 \mathrm{D}$ biofilm structure, cell arrangement and matrix shape. ESEM analysis confirmed the heterogeneous architecture of biofilm formed by S. pseudintermedius DSM 25713, and disclosed the presence of a highly hydrated extracellular matrix within the surrounding cells (Fig. 7).

\section{Discussion}

Our results demonstrate, for the first time, that human $S$. pseudintermedius has the potential to grow as an antibiotic-resistant biofilm. In fact, confocal and electron microscopy revealed that under static conditions, similarly to wound infections, S. pseudintermedius strain DSM 25713 is able to form a well-structured biofilm, consisting of multilayered, mushroom-shaped microcolonies embedded in an abundant amount of EPS matrix, 

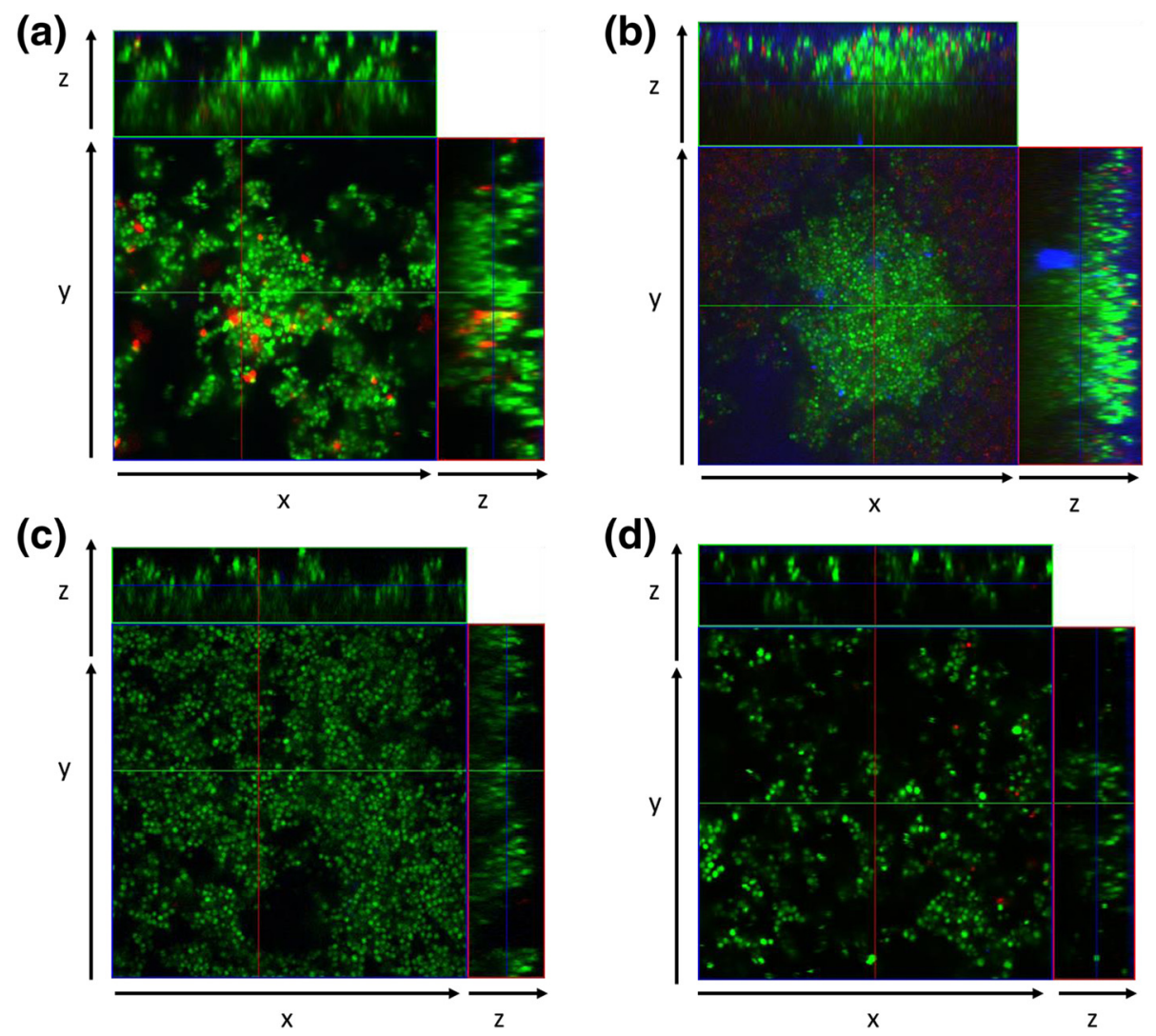

Fig. 5 Confocal Laser Scanning Microscopy of biofilm formed by S. pseudintermedius strain DSM 25713. Biofilm was allowed to form for 48 h at $37^{\circ} \mathrm{C}$, in absence of serum, under both (a) static, and (b) dynamic (flow cell chamber) conditions. Static biofilms were further treated for $24 \mathrm{~h}$ with increasing gentamicin concentrations (1x-128xMIC). Representative images of biofilm exposed at (c) 1x and (d) 128xMIC gentamicin are shown. Orthogonal images $z$ are projections of $x$ and $y$ planes, collected within the biofilm as indicated by the green and red lines in the top view. Image capture was set for simultaneous visualization of red (Propidium iodide-stained dead cells), green (Syto-9-stained viable cells), and blue (Concanavalin A-stained EPS) fluorescence. Magnification, x100

all features highly suggestive of a mature biofilm. SEM observation revealed that EPS, critical for attachment and structural development of mature biofilm [21], forms an extensive network of filaments stretching among cells as well as between cells and the polystyrene surface.

Furthermore, CLSM analysis of S. pseudintermedius biofilm formed under dynamic conditions, such as those observed inside a venous or urinary catheter, revealed a more complex ultrastructure compared with that observed under static conditions, with significant increases in both cellularity and thickness. These findings show the potential for $S$. pseudintermedius to cause an implantassociated infection, which is consistent with previous reports of S. pseudintermedius causing infections associated with intravascular devices (cardiac devices, catheters) [3-5].

The ability of bacteria to form biofilms has recently been demonstrated as a cause for the chronicization of wound infections [22-25]. Various factors may modulate in vivo biofilm development at a wound infection site
[26-29]. For example, serum proteins (i.e. fibrinogen and albumin) deposited onto host tissues provide receptor binding sites for bacterial adhesion and biofilm formation [26-28]. In addiction, wound exudate $\mathrm{pH}$, modulated during infection and healing processes, affects bacterial growth and density in biofilm populations [29]. Therefore, the present study examined the ability of the S. pseudintermedius strain DSM 25713 to form biofilms in the presence of serum and at different $\mathrm{pH}$ values, conditions relevant to the wound environment.

Our results show that the presence of human serum negatively affects $S$. pseudintermedius biofilm formation, although it is worthy to note that the ability to form biofilm was retained even in the presence of serum concentrations well above those observed at the site of infection. Our findings are in agreement with those found for S. aureus and P. aeruginosa [30, 31], but discordant with studies focused on other Gram-positive bacteria - including Streptococcus mitis, S. aureus, and coagulase-negative staphylococci - whose adherence was not significantly inhibited by serum [32-34]. 

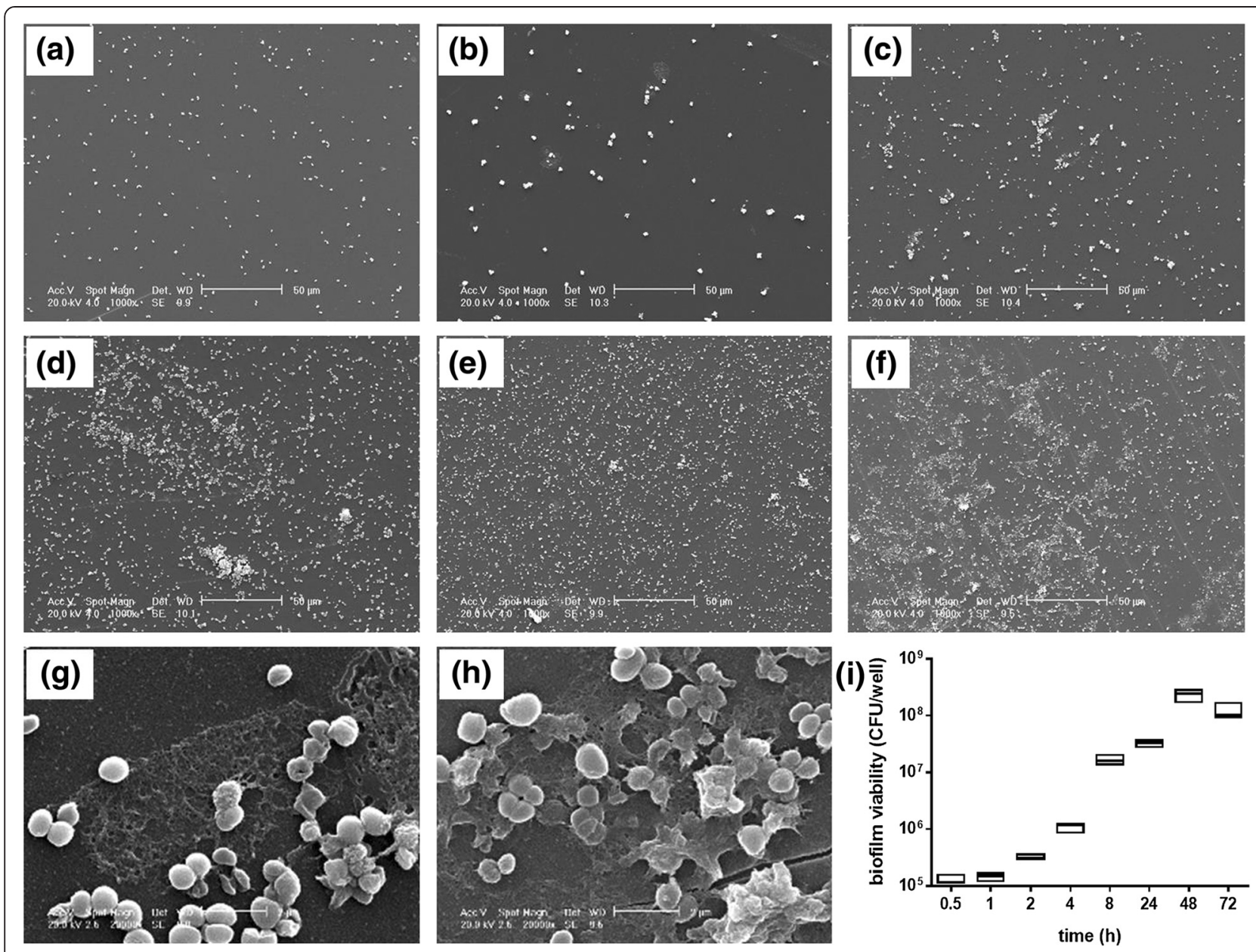

Fig. 6 Kinetic of biofilm formation, through 72 h-incubation, by S. pseudintermedius strain DSM 25713 onto polystyrene. (a-f) Representative SEM images of biofilm formation after 1, 4, 8, 24, 48, and 72 h of incubation, respectively. Magnification (x1.000). (g, h) Magnification (x20.000) of (e) and (f), respectively. Cocci are surrounded by EPS appearing as an extensive network of filaments stretched among cells and between these and the substratum. (i) Kinetic of biofilm formation as assessed by viable count. Maximum, median, and minimum values are shown in each box $(n=6)$

The anti-biofilm effect of serum is not due to antibacterial effect since, according to previous findings obtained for $P$. aeruginosa [30], serum significantly promoted the growth of S. pseudintermedius, regardless of the $\mathrm{pH}$ levels tested.

Precoating polystyrene resulted in a significant decrease in biofilm formation, when compared to the uncoated controls, even in the presence of $1 \%$ serum, thus suggesting that serum components, such as albumin, adsorbed on the substratum surface prevent bacterial attachment by acting as a physical barrier between bacteria and the substratum, or by making the surface less hydrophobic. In particular, the anti-adhesive effect of human serum albumin seems related to the competitive binding of this protein to an accretion surface or bacterial cells [35]. Further studies are warranted in this regard.

The reduction of S. pseudintermedius attachment and biofilm formation that we observed in the presence of free serum also suggests that serum might inhibit biofilm formation by additional mechanisms other than coating the surface. As previously observed for $P$. aeruginosa [30], particular components of serum could directly interact with S. pseudintermedius thus inhibiting biofilm formation.

Knowledge of the anti-biofilm activity of antibiotics is critical for the management of biofilm-related infections, such as chronic wounds. In the present work, we selected gentamicin, cefoxitin, linezolid, rifampicin, tigecycline and vancomycin because of their relevance in the prevention and treatment of staphylococcal infections, particularly those caused by methicillin-resistant $S$. aureus (MRSA). The older drugs chloramphenicol and tetracycline were also considered, since older antibiotics are frequently being re-evaluated for treatment of multi-drug resistant and biofilm-based infections, due to the decrease in development of novel antimicrobials [36].

Since the bacterial adhesion to a surface is a critical prerequisite for biofilm formation, we first investigated the prophylactic potential of the selected antibiotics by 

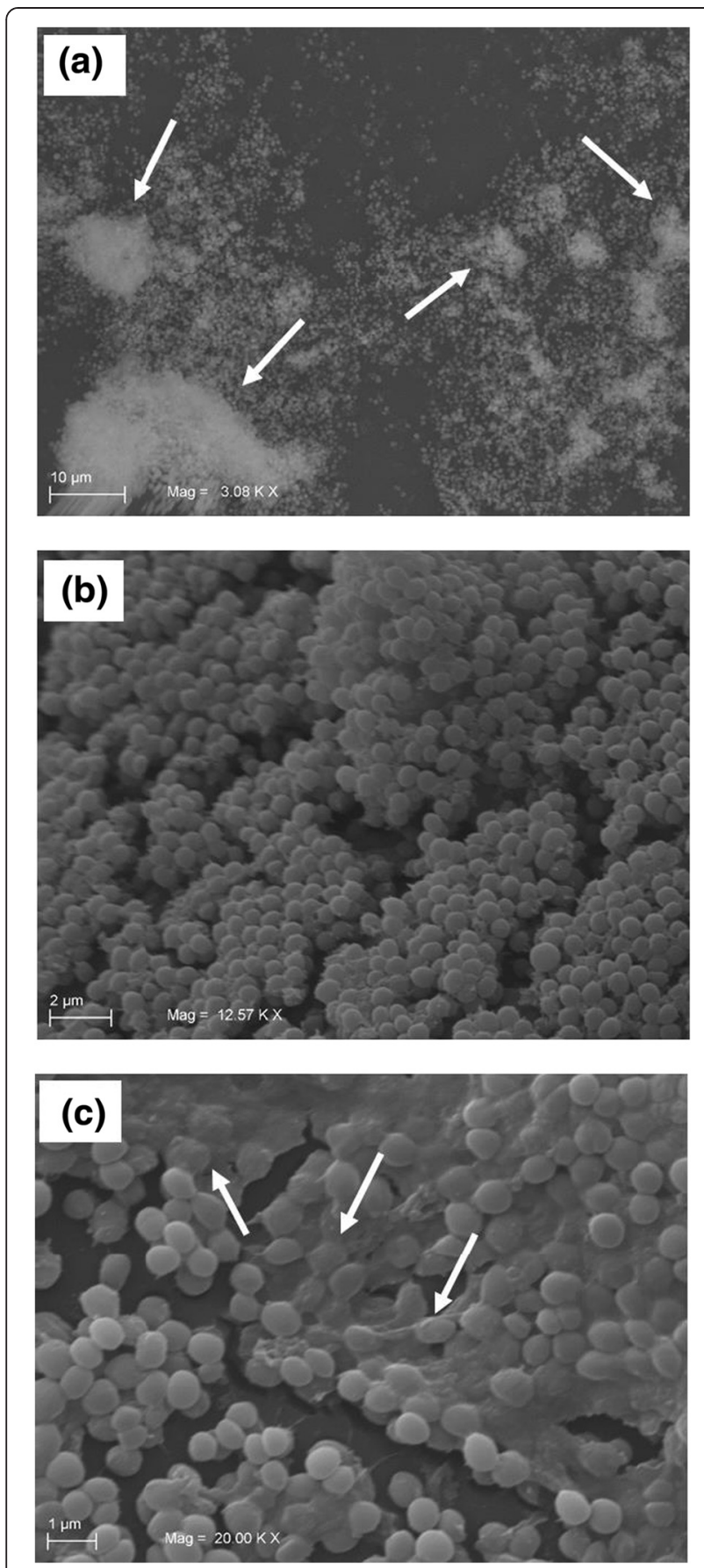

Fig. 7 ESEM images of biofilm formed by S. pseudintermedius strain DSM 25713 onto polystyrene following 72 h-incubation. (a) Biofilm exhibited spatially heterogeneous organization, as suggested by the presence of "mushroom-like" structures (as indicated by arrows). Magnification: $\times 3.000$. (b, c) Multilayered organization with the presence of bacteria under EPS matrix (as indicated by arrows). Magnification: $\times 12.500$ and $\times 20.000$, respectively

assessing the effect of sub-inhibitory concentrations against both adhesion and biofilm biomass formation. All antibiotics showed both anti-adhesive and anti-biofilm effect, although to different extents. Particularly, cefoxitin exhibited the strongest activity, demonstrating the ability to reduce biofilm biomass formation more than $90 \%$ regardless of the tested concentration. On the contrary, the smallest effect was observed for vancomycin, since it was ineffective against biofilm formation even at $1 / 8 \mathrm{x}$ and $1 / 4 \mathrm{xMIC}$. Antibiotic concentrations effective against biofilm formation were not active against planktonic growth, and no correlation was found between the ability to kill planktonic cells and the activity on biofilm formation. Together, these findings suggest that the tested antibiotics interfere with $S$. pseudintermedius biofilm formation by mechanisms other than direct antimicrobial activity.

Chronic infections, including wounds and implantassociated infections, often persist despite antibiotic therapy and the innate and adaptive immune and inflammatory responses of the host because due to the presence of biofilm-growing bacteria [37]. Clinically used antibiotics and their dose regimens were in fact classically developed to treat infections due to the presence of planktonic bacteria, therefore they are ineffective in the eradication of biofilm-based infections at the same doses. To evaluate the antibiotic activity against preformed biofilm by S. pseudintermedius strain DSM 25713, MBEC of each antibiotic was measured following $24 \mathrm{~h}$-exposure of $48 \mathrm{~h}$-old biofilms to bactericidal concentrations. Overall, MBEC values were greater than CLSI-suggested planktonic MIC breakpoint for resistance. Comparative evaluation of $\mathrm{MBEC}_{90} / \mathrm{MIC}$ ratio - an important parameter for choosing the antibiotic in the treatment of biofilm-associated infections - indicated rifampicin as the most active antibiotic $\left(\mathrm{MBEC}_{90} / \mathrm{MIC}\right.$ : 2 ), in agreement with previous in vitro and in vivo studies focused on S. aureus biofilm [38, 39]. Other antibiotics tested showed a significantly reduced activity against preformed S. pseudintermedius biofilm as suggested by $\mathrm{MBEC}_{90}$ values ranging from 16xMIC (vancomycin) to at least $128 x$ MIC (linezolid, tigecycline, chloramphenicol, and tetracycline). In agreement with our findings, Leite et al. [40] found that rifampicin was more active than linezolid against $S$. epidermidis biofilms, while Parra-Ruiz et al. [41] observed that linezolid was not bactericidal against mature biofilms formed by $S$. aureus. Our results with $S$. pseudintermedius biofilms are consistent with the findings of vancomycin antibiotic-lock resistant catheter-associated S. pseudintermedius bacteremia described by Chuang et al. [4], being due to the presence of resistant biofilms.

The clinical relevance of our results is even more evident if peak serum antibiotic concentrations are considered. With the exception of rifampicin, none of the tested antibiotics would have been able to eradicate biofilm even when used at multiples of achievable serum levels from currently recommended dosages. In particular, chloramphenicol, 
tigecycline, cefoxitin, and linezolid required from 23 to 256 times the maximum attainable concentration in serum to achieve $90 \%$-inhibition of biofilm viability. The relative lack of efficacy of linezolid and tigecycline in eradicating S. pseudintermedius cells embedded in biofilm is consistent with prior in vitro studies concerning staphylococcal biofilms [42, 43], raising a special clinical concern since these antibiotics are used as the "treatment of last resort" against potentially lifethreatening MRSA infections that are sometimes not treatable with any other antibiotics.

The mechanisms of biofilm resistance are likely multifactorial and vary according to the considered specie, and remain still unclear [44]. Although the present work was not focused on mechanisms underlying the inherent antibiotic-resistance of $S$. pseudintermedius biofilm, the complex biofilm structure, as revealed by microscopic analysis, might play a role in this regard by physically/ chemically sequestering the antibiotic, thus delaying its penetration through the biofilm.

Gentamycin, whose $\mathrm{MBEC}_{90}$ is 2.6 to 6.4 times higher than peak serum, may be an example of this, where interactions between the positively charged antibiotic and the negatively charged components of EPS likely are responsible for preventing ready diffusion of the antimicrobials through the biofilm matrix to the bacteria [44]. Despite the potential inherent resistance of biofilms to aminoglycosides, the increased concentrations afforded by topical therapy $[7,45]$, or treatment of wounds where aminoglycosides are relatively concentrated [46], may still allow for the successful eradication of biofilm infections.

\section{Conclusions}

Some clinical implications can be drawn on the basis of our results. First, while S. pseudintermedius is a commensal in dogs, our results show significant concern for the organism as a pathogen in people, especially when associated with temporary or permanent implants [3-5]. Second, serum reduces, but does not prevent, S. pseudintermedius biofilm formation at concentrations measured in infected wound exudate. Third, S. pseudintermedius is able to form mature biofilm inherently resistant to antibiotics at concentrations well above those observed in serum, including linezolid, tigecycline, and vancomycin which are commonly considered as "last resort antibiotics" against methicillin-resistant staphylococci. This is particularly relevant in chronic GvHD patients where skin wound infections account for the majority of deaths [47]. Fourth, in vitro models relevant to the in vivo situation are needed for adequately assessing antibiotic activity in the case of biofilm-related infections, such as for wounds. Using our model, rifampicin was measured to be the most effective antibiotic against S. pseudintermedius strain DSM 25713 biofilms, however clinical use of rifampicin as a sole agent should be appreciated cautiously due to the rapid selection of rifampicin-resistant mutants [48].

The data presented here are in vitro results and, therefore, cannot completely explain or represent S. pseudintermedius biofilm-related infections. Both in vitro and in vivo models representative of the wound environment are required to gain new insights into the mechanisms underlying bacterial adhesion and biofilm formation aimed at designing new therapeutic strategies.

\section{Abbreviations}

ICD: Implantation of a cardioverter-defribrillator device; GVHD: Graft-versusHost Disease; DSM: Deutsche Sammlung von Mikroorganismen und Zellkulturen, GmbH); EPS: Extracellular polymer substance; TSB: Trypticase soy broth; MHA: Mueller-Hinton Agar; OD: Optical density; MBEC: Minimum biofilm eradication concentration; CAMHB: Cation-Adjusted Mueller-Hinton Broth; SEM: Scanning electron microscopy; ESEM: Environmental-SEM; CLSM: Confocal laser scanning microscopy; SBF: Specific biofilm formation; MRSA: Methicillin-resistant Staphylococcus aureus.

\section{Competing interests}

The authors declare that they have no competing interests.

\section{Authors' contributions}

AP, SDN, and VC performed experimental activity concerning the standardization of the in vitro biofilm model, the effect of serum and $\mathrm{pH}$ on biofilm formation, the in vitro activity against biofilm formation and preformed biofilms. AP has taken care of electron microscopy and, together with SG, of confocal microscopy analysis. EC and VS performed susceptibility assays. VS collected clinical strains used in the present work and contributed by giving a medical point of view to the discussion of the results. GDB and AP performed statistical analysis, were involved in the design of the study, and drafted the manuscript. GDB gave their final approval of the version to be published. All authors read and approved the final manuscript.

\section{Aknowledgements}

The Authors desire to thank Sarah Markland, Department of Animal and Food Sciences, University of Delaware for English manuscript editing. This work was supported by the "G. d'Annunzio" University of Chieti-Pescara grant (quota "ex-60 \%", anno 2012-2013). We thank Fabrizia Musella for technical assistance.

\section{Author details}

"Department of Medical, Oral, and Biotechnological Sciences, "G. d'Annunzio" University, Via Vestini 31, Chieti 66100, Italy. ${ }^{2}$ Center for Research on Ageing, "G. d'Annunzio" University Foundation, Chieti, Italy. ${ }^{3}$ Department of Neuroscience and Imaging, "G. d'Annunzio" University, Chieti, Italy. ${ }^{4}$ Clinical Microbiology and Virology, "Spirito Santo" Hospital, Pescara, Italy. ${ }^{5}$ IRCCS Arcispedale, "Santa Maria Nuova", Reggio Emilia, Italy.

Received: 20 October 2014 Accepted: 15 May 2015

Published online: 21 May 2015

\section{References}

1. Bannoehr J, Guardabassi L. Staphylococcus pseudintermedius in the dog: taxonomy, diagnostics, ecology, epidemiology and pathogenicity. Vet Dermatol. 2012;23(4):253-66.

2. Devriese LA, Hermans K, Baele M, Haesebrouck F. Staphylococcus pseudintermedius versus Staphylococcus intermedius. Vet Microbiol. 2009;133:206-7.

3. van Hoovels L, Vankeerberghen A, Boel A, Van Vaerenbergh K, De Beenhouwer H. First case of Staphylococcus pseudintermedius infection in a human. J Clin Microbiol. 2006;44:4609-12.

4. Chuang CY, Yang YL, Hsueh PR, Lee PI. Catheter-related bacteremia caused by Staphylococcus pseudintermedius refractory to antibioticlock therapy in a hemophilic child with dog exposure. J Clin Microbiol. 2010;48:1497-8.

5. Riegel P, Jesel-Morel L, Laventie B, Boisset S, Vandenesch F, Prévost G. Coagulase positive Staphylococcus pseudintermedius from animals causing human endocarditis. Int J Med Microbiol. 2010;301:237-9. 
6. Stegmann R, Burnens A, Maranta CA, Perreten V. Human infection associated with methicillin-resistant Staphylococcus pseudintermedius ST71. J Antimicrob Chemother. 2009;65:2047-8.

7. Savini V, Barbarini D, Polakowska K, Gherardi G, Białecka A, Kasprowicz A, et al. Methicillin-resistant Staphylococcus pseudintermedius infection in a bone marrow transplant recipient. J Clin Microbiol. 2013:51:1636-8.

8. Garbacz K, Zarnowska S, Piechowicz L, Haras K. Pathogenicity potential of Staphylococcus pseudintermedius strains isolated from canine carriers and from dogs with infection signs. Virulence. 2013;4:255-9.

9. Tanabe T, Toyoguchi M, Hirano F, Chiba M, Onuma K, Sato H. Prevalence of staphylococcal enterotoxins in Staphylococcus pseudintermedius isolates from dogs with pyoderma and healthy dogs. Microbiol Immunol. 2013:57:651-4.

10. van Duijkeren E, Catry B, Greko C, Moreno MA, Pomba MC, Pyörälä S, et al. Scientific Advisory Group on Antimicrobials (SAGAM): review on methicillinresistant Staphylococcus pseudintermedius. J Antimicrob Chemother. 2011;66:2705-14.

11. Otto M. Staphylococcal infections: mechanisms of biofilm maturation and detachment as critical determinants of pathogenicity. Annu Rev Med. 2013;64:175-88.

12. Osland AM, Vestby LK, Fanuelsen H, Slettemeås JS, Sunde M. Clonal diversity and biofilm-forming ability of methicillin-resistant Staphylococcus pseudintermedius. J Antimicrob Chemother. 2012;67:841-8.

13. Bardiau M, Yamazaki K, Ote I, Misawa N, Mainil JG. Characterization of methicillin-resistant Staphylococcus pseudintermedius isolated from dogs and cats. Microbiol Immunol. 2013;57:496-501.

14. Singh A, Walker M, Rousseau J, Weese JS. Characterization of the biofilm forming ability of Staphylococcus pseudintermedius from dogs. BMC Vet Res. 2013;9:93.

15. Pompilio A, Pomponio S, Crocetta V, Gherardi G, Verginelli F, Fiscarelli E, et al. Phenotypic and genotypic characterization of Stenotrophomonas maltophilia isolates from patients with cystic fibrosis: genome diversity, biofilm formation, and virulence. BMC Microbiol. 2011;11:159.

16. Hucker GJ. A new modification and application of the Gram stain. J Bacteriol. 1921;6:395-7.

17. Tolker-Nielsen T, Sternberg C: Growing and analyzing biofilms in flow chambers. Curr Prot Microbiol 2011, Chapter 1: Unit 1B.2.

18. lizaka S, Sanada H, Nakagami G, Sekine R, Koyanagi H, Konya C, et al Estimation of protein loss from wound fluid in older patients with severe pressure ulcers. Nutrition. 2010;26:890-5.

19. Clinical and Laboratory Standards Institute Performance standards for antimicrobial susceptibility texting; sixteenth informational supplement. CLSI document M100-S20. Clinical and Laboratory Standards Institute (2010).

20. Stepanović S, Vuković D, Hola V, Di Bonaventura G, Djukić S, Cirković I, et al. Quantification of biofilm in microtiter plates: overview of testing conditions and practical recommendations for assessment of biofilm production by staphylococci. APMIS. 2007;115:891-9.

21. Flemming HC, Wingender J. The biofilm matrix. Nat Rev Microbiol. 2010;8(9):623-33

22. Akers KS, Mende K, Cheatle KA, Zera WC, Yu X, Beckius ML, et al. Infectious disease clinical research program trauma Infectious disease outcomes study group: biofilms and persistent wound infections in United States military trauma patients: a case-control analysis. BMC Infect Dis. 2014;14:190.

23. Percival SL, Emanuel C, Cutting KF, Williams DW. Microbiology of the skin and the role of biofilms in infection. Int Wound J. 2012;9(1):14-32.

24. Davis SC, Ricotti C, Cazzaniga A, Welsh E, Eaglstein WH, Mertz PM. Microscopic and physiologic evidence for biofilm-associated wound colonisation in vivo. Wound Repair Regen. 2008;16:23-9.

25. Malic S, Hill KE, Hayes A, Percival SL, Thomas DW, Williams DW. Detection and identification of specific bacteria in wound biofilms using peptide nucleic acid (PNA) fluorescent in situ hybridisation (FISH). Microbiology. 2009;155:2603-11.

26. Wagner C, Aytac S, Hänsch GM. Biofilm growth on implants: bacteria prefer plasma coats. Int J Artif Organs. 2011;34(9):811-7.

27. O'Neill E, Pozzi C, Houston P, Humphreys H, Robinson DA, Loughman A et al. A novel Staphylococcus aureus biofilm phenotype mediated by the fibronectin-binding proteins, FnBPA and FnBPB. J Bacteriol. 2008;190:3835-50

28. Pihl M, Arvidsson A, Skepö M, Nilsson M, Givskov M, Tolker-Nielsen T, et al. Biofilm formation by Staphylococcus epidermidis on peritoneal dialysis catheters and the effects of extracellular products from Pseudomonas aeruginosa. Pathog Dis. 2013;67(3):192-8.

29. Percival SL, McCarty S, Hunt JA, Woods EJ. The effects of pH on wound healing, biofilms, and antimicrobial efficacy. Wound Repair Regen. 2014;22(2):174-86

30. Hammond A, Dertien J, Colmer-Hamood JA, Griswold JA, Hamood AN. Serum inhibits $P$. aeruginosa biofilm formation on plastic surfaces and intravenous catheters. J Surg Res. 2010;159:735-46.

31. Werthén $M$, Henriksson L, Jensen $P \varnothing$, Sternberg C, Givskov M, Bjarnsholt T. An in vitro model of bacterial infections in wounds and other soft tissues. APMIS. 2010;118:156-64.

32. Paulsson $M$, Kober M, Freij-Larsson C, Stollenwerk M, Wesslén B, Ljungh A. Adhesion of staphylococci to chemically modified and native polymers, and the influence of preadsorbed fibronectin, vitronectin and fibrinogen. Biomaterials. 1993;14:845-53.

33. Müller R, Gröger G, Hiller KA, Schmalz G, Ruhl S. Fluorescence-based bacterial overlay method for simultaneous in situ quantification of surface-attached bacteria. Appl Environ Microbiol. 2007;73:2653-60.

34. Dorkhan M, de Paz LE C, Skepö M, Svensäter G, Davies JR. Effects of saliva or serum coating on adherence of Streptococcus oralis strains to titanium Microbiology. 2012;158:390-7.

35. Donlan RM, Costerton JW. Biofilms: survival mechanisms of clinically relevant microorganisms. Clin Microbiol Rev. 2002;15:167-93.

36. Falagas ME, Grammatikos AP, Michalopoulos A. Potential of old-generation antibiotics to address current need for new antibiotics. Expert Rev Anti Infect Ther. 2008;6:593-600.

37. Scali C, Kunimoto B. An update on chronic wounds and the role of biofilms. J Cutan Med Surg. 2013;17(6):371-6.

38. Mihailescu R, Furustrand Tafin U, Corvec S, Oliva A, Betrisey B, Borens O, et al. High activity of fosfomycin and rifampin against methicillin-resistant Staphylococcus aureus biofilm in vitro and in an experimental foreign-body infection model. Antimicrob Agents Chemother. 2014;58(5):2547-53.

39. Bauer J, Siala W, Tulkens PM, Van Bambeke F. A combined pharmacodynamic quantitative and qualitative model reveals the potent activity of daptomycin and delafloxacin against Staphylococcus aureus biofilms. Antimicrob Agents Chemother. 2013;57(6):2726-37.

40. Leite B, Gomes F, Teixeira P, Souza C, Pizzolitto E, Oliveira R. In vitro activity of daptomycin, linezolid and rifampicin on Staphylococcus epidermidis biofilms. Curr Microbiol. 2011;63:313-7.

41. Parra-Ruiz J, Bravo-Molina A, Peña-Monje A, Hernández-Quero J. Activity of linezolid and high-dose daptomycin, alone or in combination, in an in vitro model of Staphylococcus aureus biofilm. J Antimicrob Chemother. 2012;67:2682-5.

42. McConeghy $\mathrm{KW}$, LaPlante KL. In vitro activity of tigecycline in combination with gentamicin against biofilm-forming Staphylococcus aureus. Diagn Microbiol Infect Dis. 2010;68(1):1-6.

43. Molina-Manso D, del Prado G, Ortiz-Pérez A, Manrubia-Cobo M, GómezBarrena E, Cordero-Ampuero J, et al. In vitro susceptibility to antibiotics of staphylococci in biofilms isolated from orthopaedic infections. Int J Antimicrob Agents. 2013;41:521-3.

44. Høiby N, Bjarnsholt T, Givskov M, Molin S, Ciofu O. Antibiotic resistance of bacterial biofilms. Int J Antimicrob Agents. 2010;35:322-32.

45. Lipsky BA, Hoey C. Topical antimicrobial therapy for treating chronic wounds. Clin Infect Dis. 2009;49:1541-9.

46. Friberg O, Jones I, Sjöberg L, Söderquist B, Vikerfors T, Källman J. Antibiotic concentrations in serum and wound fluid after local gentamicin or intravenous dicloxacillin prophylaxis in cardiac surgery. Scand J Infect Dis. 2003:35:251-4

47. Hasse B, Husmann L, Zinkernagel A, Weber R, Lachat M, Mayer D. Vascular graft infections. Swiss Med Wkly. 2013;24(143):w13754.

48. Anstead GM, Cadena J, Javeri $\mathrm{H}$. Treatment of infections due to resistant Staphylococcus aureus. Methods Mol Biol . 1989;1085:259-309.

49. Stein CM, Thornhill DP, Neill P, Nyazema NZ. Lack of effect of paracetamol on the pharmacokinetics of chloramphenico. Br J Clin Pharmaco. 1989;27:262-4

50. Wilson JW, Estes LL. Mayo Clinic Antimicrobial Therapy Quick Guide. USA: Mayo Clinic Scientific Press and Informa Healthcare; 2008.

51. Jaresko GS, Barriere SL, Johnson Jr BL. Serum and blister fluid pharmacokinetics and bactericidal activities of ampicillin-sulbactam, cefotetan, cefoxitin, ceftizoxime, and ticarcillin-clavulanate. Antimicrob Agents Chemother. 1992;36:2233-8. 
52. Manfredi R. Update on the appropriate use of linezolid in clinical practice. Ther Clin Risk Manag. 2006;2:455-64.

53. Acocella G. Pharmacokinetics and metabolism of rifampin in humans. Rev Infect Dis. 1983;5:S428-32.

54. Giamarellou H, Poulakou G. Pharmacokinetic and pharmacodynamic evaluation of tigecycline. Expert Opin Drug Metab Toxicol. 2011;7:1459-70.

55. Eisen D: Tetracycline. In: Kucers' the use of antibiotics. Edited by Grayson ML, Crowe SM, McCarthy, JS. London: Hodder Arnold; 2010: 843-851.

56. Rybak M, Lomaestro B, Rotschafer JC, Moellering Jr R, Craig W, Billeter M, et al. Therapeutic drug monitoring of vancomycin in adult patients: a consensus review of the American society of health-system Pharmacists, the infectious diseases society of America, and the society of infectious diseases Pharmacists. Am J Health Syst Pharm. 2009;66:82-98.

\section{Submit your next manuscript to BioMed Central and take full advantage of:}

- Convenient online submission

- Thorough peer review

- No space constraints or color figure charges

- Immediate publication on acceptance

- Inclusion in PubMed, CAS, Scopus and Google Scholar

- Research which is freely available for redistribution 